\title{
Phenology of Apothecium Production in Populations of Monilinia vaccinii-corymbosi from Early- and Late-Maturing Blueberry Cultivars
}

\author{
Jeffrey S. Lehman and Peter V. Oudemans
}

First author: Otterbein College, Department of Life and Earth Sciences, Westerville, OH 43081; and second author: Rutgers University, Blueberry and Cranberry Research and Extension Center, Lake Oswego Rd. Chatsworth, NJ 08019.

Accepted for publication 14 October 1996.

\begin{abstract}
Lehman, J. S., and Oudemans, P. V. 1997. Phenology of apothecium production in populations of Monilinia vaccinii-corymbosi from early- and late-maturing blueberry cultivars. Phytopathology 87:218-223.

Pseudosclerotia were evaluated for differences in timing of apothecium development in four controlled experiments conducted over a 2-year period. In a separate experiment, conidia from 10 randomly selected isolates from both of the fungal populations were used to inoculate open flowers. Germination of pseudosclerotia produced from these artificial inoculations also was evaluated. The timing and rate of shoot elongation for cvs. Weymouth and Jersey were assessed in one greenhouse and two field experiments. Average development times for the fungal population from cv. Weymouth were 8 to 15 days earlier or 33 to $42 \%$ less than those for the population from cv. Jersey. The fungal population from Weymouth also exhibited less variation in development times for each
\end{abstract}

ABSTRACT developmental stage measured. Similarly, germination of pseudosclerotia produced in artificial inoculations differed between populations. On average, pseudosclerotia derived from the Weymouth population produced apothecia 16 days earlier. During spring 1995 and 1996, vegetative and truss buds on cv. Weymouth developed 4 to 16 days earlier than those on cv. Jersey. These results demonstrate that $M$. vaccinii-corymbosi exhibits variation in timing of pseudosclerotia germination and apothecium development within and between populations. We hypothesize that differences observed in the timing of apothecium development are related to the fitness of the populations on their original host cultivars and were selected by host phenology.

Additional keywords: fungal adaptation, fungal fitness, mummy berry disease, phenological development.
Mummy berry disease, caused by Monilinia vaccinii-corymbosi (Reade) Honey, occurs in commercial and native stands of Vaccinium spp. throughout North America and northern Europe (8, 12). The disease reduces yield by blighting newly formed vegetative and flower truss buds (primary infection) or causing hard rot of fruit (secondary infection). These two phases of the disease cycle are caused by ascospore and conidial infections, respectively (24).

The disease is initiated during the spring when pseudosclerotia, the overwintering structure of $M$. vaccinii-corymbosi, germinate and produce apothecia from which ascospores are discharged. The process of germination begins with the production of stipe initials (i.e., small projections from the pseudosclerotium that later form stalks on which the disks of the apothecia develop). Stipe initials elongate and eventually form apical invaginations or dimples that give individual stipes the appearance of a finishing nail. The apical tip of the stipe expands and forms a hollow, bulblike swelling. Eventually, the tip of the stipe forms an urnulate disk with a distinct inrolled margin. This goblet-like structure continues to expand and develops into mature apothecium and ascospores (3). Wind-blown ascospores infect breaking buds and young elongating shoots of blueberry hosts (Vaccinium spp.) (21,22). Conidia produced from these primary infections are carried to the styles, where conidia germinate and infect the ovary (17). Infected flowers become ramified with fungal tissue and form a mummified fruit (pseudosclerotium).

Corresponding author: P. V. Oudemans

E-mail address: oudemans@ @esop.rutgers.edu

Publication no. P-1997-0113-02R

(C) 1997 The American Phytopathological Society
Resistance to both the primary and secondary phases of the disease has been identified $(11,18,20,23,24)$; however, results of germplasm surveys vary across environments $(20,23)$. Some studies have indicated that timing of bud break, as measured by host shoot length, and disease resistance are negatively correlated (11, 20). Thus, disease avoidance may provide a significant portion of resistance to the mummy berry pathogen in blueberries.

Disease avoidance differs from disease escape in that avoidance is the result of host genotype, whereas escape is a random process (6). Because of the genetic basis of disease avoidance, pathogens potentially can adapt to avoidance mechanisms provided pathogen populations exhibit variation to these traits (6). In a broader context, the specialization of Monilinia spp. to host species in the subfamily Vacciniodeae may be due, in part, to the adaptation of pathogen phenologies to coordinate with those of divergent hosts. Batra (2) reported differences in apothecium development among populations of $M$. vaccinii-corymbosi and M. gaylussacia, two closely related fungal species with similar life cycles and related host species. The results of Batra's (2) work over a 3-year period demonstrated that apothecial formation of M. vaccinii-corymbosi was consistently 10 to 16 days earlier than M. gaylussacia (2). This difference corresponds to the difference in the phenologies of the two host species located at the same site.

It is unknown whether populations of M. vaccinii-corymbosi adapt to the phenologies of highbush blueberry cultivars or how host and pathogen phenologies influence disease. Host blueberry cultivars with varied phenologies could impose selection pressure for pathogen isolates with corresponding phenologies because of a greater likelihood for infection compared to early- or late-developing isolates. Such isolates would have a reproductive advantage, enabling them to increase in frequency and potentially change the average phenology of the population, provided pathogen phenol- 
ogy is heritable. To determine how host and pathogen phenologies influence disease, we have been studying the variation in timing of apothecium development for populations of M. vaccinii-corymbosi and how it coordinates with the timing of host bud break and shoot development. The specific objectives of our study were to determine whether differences in phenological development exist between blueberry cultivars and between pathogen populations and whether evidence exists for adaptation of pathogen populations to the phenology of different cultivars.

\section{MATERIALS AND METHODS}

Wild-type populations of $M$. vaccinii-corymbosi. Two populations of M. vaccinii-corymbosi, 9420-WT and 9421-WT, were collected in 1994 and 1995 from naturally infected blueberry bushes growing near Chatsworth, NJ (15). Pseudosclerotia of population 9420-WT were collected from bushes of early-fruiting cv. Weymouth (10) that had been in continuous commercial production for more than 40 years. Pseudosclerotial density at the collection site was 5 to 15 per bush despite spring applications of the fungicide triforine. Pseudosclerotia of population 9421-WT were collected from late-fruiting cv. Jersey (10). Bushes at the site were also more than 40 years old but had not been in commercial production for $\sim 15$ years. Pseudosclerotial density was one to five per bush. Pseudosclerotia collected from these populations were used in a greenhouse to evaluate the phenological (experiments I through III) and morphological development (experiment IV) of M. vaccinii-corymbosi.

Conditions for apothecial production. In all greenhouse experiments, pseudosclerotia from individual collection sites were buried approximately $0.5 \mathrm{~cm}$ below the surface of moist soil (washed sand/peat moss, $1: 1$, by volume) in $17 \times 38-\mathrm{cm}$ flats. Wire screen was positioned over the pseudosclerotia, and moist sphagnum moss was placed over the screen. Flats were watered and maintained in a greenhouse at 20 to $27^{\circ} \mathrm{C}$ with natural lighting for 1 month and then moved outside at ambient temperatures to fulfill the chilling requirement of the pseudosclerotia $(5,16)$. The sphagnum moss and screen were removed from the flats on 19 February 1995 (experiments I, II, and IV) and 19 January 1996 (experiment III) after pseudosclerotia had received $\sim 1,200$ hours between 0 and $7^{\circ} \mathrm{C}$. Flats were immediately transferred to a greenhouse at $15^{\circ} \mathrm{C}$ to initiate pseudosclerotial germination and apothecium production. In addition to natural lighting, flats received 12 hours of supplemental fluorescent lighting per day.

Pseudosclerotial germination and apothecium development. Pseudosclerotia were monitored daily throughout the germination and apothecium development period. Mean development times for each fungal population were determined from daily counts of the number of newly formed stipes, invaginated stipes, expanding stipes, or mature apothecia. Development times, expressed as days at $15^{\circ} \mathrm{C}$, were calculated as the weighted mean time from the equation

$$
\text { mean development time }=\sum_{i=0}^{n} P_{i} t_{i}
$$

where $P_{i}$ is the proportion of newly formed stipes, invaginated stipes, expanding stipes, or mature apothecia that appear on the $i^{\text {th }}$ day at $15^{\circ} \mathrm{C}$ relative to the final number of individuals in these developmental stages, $t_{i}$ is the $i^{\text {th }}$ day at $15^{\circ} \mathrm{C}$, and $n$ is the number of days at $15^{\circ} \mathrm{C}$ when the maximum number of individuals from each developmental stage have appeared. In addition, we calculated the variance of the distribution of development times for fungal structures from the equation

$$
\text { variance }=\sum_{i=0}^{n} P_{i} t_{i}^{2}-\left(\sum_{i=0}^{n} P_{i} t_{i}\right)^{2}
$$

Development rates for pseudosclerotium germination and apothecium production. The rate of development for each stage of pseudosclerotial germination was calculated from the cumula- tive values of the relative number of developmental structures present on each day. Cumulative values $(Y)$ were transformed with a Gompertz-transformation (Gompertz $Y=-1 \ln (-\ln (Y)$ ) (7), and regression analysis was used to fit a straight-line equation. Slopes of the equations approximate the rate at which developmental structures were formed for a population of pseudosclerotia. The $\mathrm{x}$ intercepts from the regression equations were used to calculate differences in the development times for each stage of germination.

Width of the uppermost portion of 10 random stipes was measured at 2- to 3-day intervals throughout apothecium development. Rates of expansion for stipe apices were calculated from width data that were log-transformed to linearize the relationship between width and time. Least squares regression equations were fit to calculate the slopes and $\mathrm{X}$-intercepts.

Artificial inoculations. Cultures of $M$. vaccinii-corymbosi were isolated from each fungal population by surface-sterilizing pseudosclerotia for $5 \mathrm{~min}$ in a $95 \%$ ethanol/5\% sodium hypochlorite solution (1:1, by volume) and placing pseudosclerotia on potato dextrose agar. Pure-cultured isolates were plated on cellulose membranes (Gelman Sciences, Ann Arbor, MI) on V8 agar to induce conidium production (4). Conidia were collected by vacuuming the colony surface with a Pasteur pipette inserted in the end of a piece of rubber tubing (5 $\mathrm{mm}$ inner diameter) attached to a vacuum pump. Conidia were filtered out of the air flow with a 3-mm syringe filter (Micron Separations, Inc., Westboro, MA) inserted in the air line between the pipette and pump and then were mixed with roughly equal amounts of pollen from blueberry cv. Bluecrop. Flowers of cv. Jersey were inoculated in the greenhouse by transferring dry conidia/pollen to the stigmatic surfaces of open flowers with a fine glass rod. Infected flowers developed into pseudosclerotia. The development of mature apothecia from pseudosclerotia of both populations was assessed as described earlier for experiment III.

Morphological measurements of fungal apothecia. In experiment IV, the final dimensions of the mature, fully formed apothecia were measured after a distinct margin formed on the cup's outer edge. Apothecia were clipped from the pseudosclerotia, and dimensions of the apothecium were measured. Characteristics measured included diameter and depth (inner and outer) of a fully expanded cup, width of the stipe 3 to $5 \mathrm{~mm}$ below the cup portion of the apothecium, length of the stalk supporting the apothecial cup, and overall height of the apothecium. Morphological dimensions of about 350 newly formed apothecia from each fungal population were measured.

Host development. The phenological development of plants of cvs. Weymouth and Jersey were measured in three field experiments during the spring of 1995 and 1996 and one greenhouse experiment during the spring of 1996. The field experiments were conducted at three locations in Burlington County, NJ, including the original collection site for populations 9420-WT and 9421WT. The plants at two of the locations were established bushes, whereas plants at the third location were 2-year-old bushes. At each location, shoot length was measured for elongating buds at 5to 7-day intervals. Lengths were log-transformed to linearize the relationship between shoot length and time. Least squares regression equations were fit to calculate slopes and x-intercepts. The slopes and $\mathrm{x}$-intercepts were used to estimate the rate and timing of shoot elongation, respectively, for cvs. Weymouth and Jersey.

In the greenhouse experiment, 2-year-old potted plants of cvs. Weymouth and Jersey were moved to a greenhouse maintained at $15^{\circ} \mathrm{C}$ on 19 January 1996 after receiving 1,100 to 1,200 hours between 0 and $7^{\circ} \mathrm{C}$ in an unheated screenhouse. Shoot length was recorded and analyzed as previously described.

Statistical analyses. Experiments I through III were randomized complete block designs with two fungal populations and either eight (experiments I and II) or five replications (experiment III). Blocks were locations on a greenhouse bench. Each experimental 
unit was composed of 50 pseudosclerotia. Because the number of replications within experiments was unequal, the combined analyses of experiments I through III were performed on treatment means averaged across replication within experiments (i.e., unweighted mean analysis) $(9,19)$. Unweighted mean analyses were used to compare fungal populations 9420-WT and 9421-WT for differences in timing and rate of pseudosclerotial germination and apothecium production. The artificial inoculation experiment was a randomized complete block design of three replications and two populations. Only the development time for the production of mature apothecia and its variance were compared for this experiment. Analysis of variance was used to compare fungal populations 9420WT and 9421-WT for morphological differences (experiment IV). Experiment IV employed a completely randomized design with four replications and two fungal populations. Each experimental unit was composed of 100 pseudosclerotia.

Unweighted mean analyses (previously described) of four experiments also were used to compare shoot elongation. The individual experiments within these analyses were completely randomized designs of three to five replications and two fungal populations. Each replication included a sample of 5 to 15 vegetative buds from the same plant.

\section{RESULTS}

Pseudosclerotial germination and apothecium development. The proportion of pseudosclerotia that germinated was similar across all experiments ( 0.5 to 0.6$)$ and did not differ for fungal populations $(P=0.54)$. Percent germination was similar to pre-

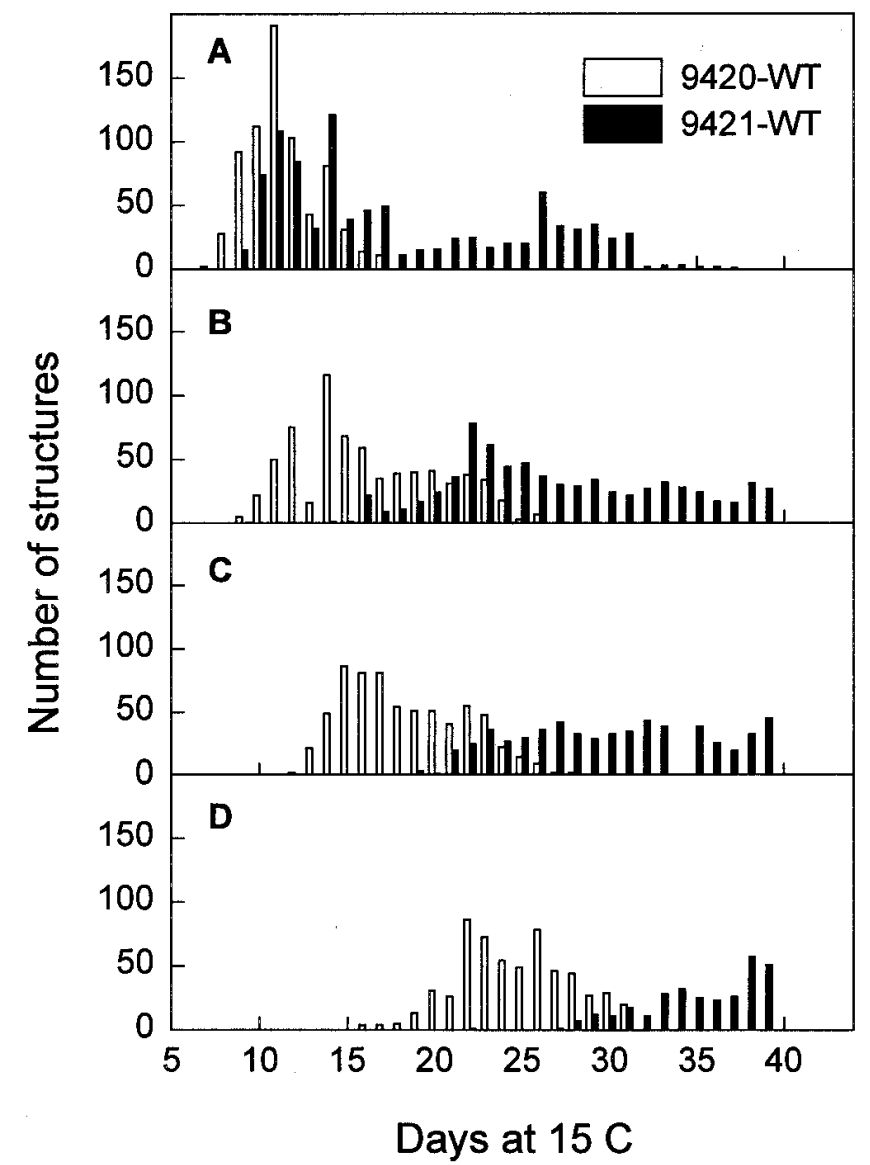

Fig. 1. Daily formation of A, newly formed stipes; $\mathbf{B}$, invaginated stipes; $\mathbf{C}$, expanding stipes; or D, mature apothecia from pseudosclerotia of Monilinia vaccinii-corymbosi. Populations 9420-WT and 9421-WT were collected from early- and late-maturing blueberry cvs. Weymouth and Jersey, respectively. Distributions are for the development of 400 pseudosclerotia from each population in experiment I. vious reports conducted under different environmental conditions $(5,17)$. Within a population of pseudosclerotia, germination was not synchronous. Rather, the production of newly formed stipes, invaginated stipes, expanding stipes, or mature apothecia occurred over a period of days. In general, the daily distribution of newly formed structures approximated a normal distribution (Fig. 1A through D) and, therefore, could be summarized by the mean and variance of the distribution indicative of its timing and uniformity, respectively.

Differences in development times for fungal populations 9420WT and 9421-WT were significant for all stages of germination $(P<0.001$ for individual analyses of experiments; $P=0.01$ to 0.03 for combined analyses of experiments). In the combined analyses, the average development times for fungal population 9420-WT were 8 to 15 days earlier than those for population 9421-WT (Table 1). The smallest difference in development time between fungal populations was observed in the production of stipes.

Variances for developmental distributions ranged from 12 to 70 days. Except for the production of mature apothecia, variances for development of population 9421-WT were significantly larger than those for population 9420-WT $(P<0.001$ for individual analyses of experiments; $P=0.02-0.04$ for combined analyses of experiments). The greatest difference was in the production of stipes, in which population 9420 -WT exhibited almost one-half the variation exhibited by population 9421-WT.

Data from experiment I are presented graphically to demonstrate the variation in pseudosclerotial germination within and between fungal populations (Fig. 1). Results for experiments II and III were similar to experiment I. In experiment I, population 9421WT produced above-ground stipes from days 9 to 37 at $15^{\circ} \mathrm{C}$ (Fig. 1A). Population 9420-WT produced stipes from days 7 to 18 (Fig. 1A). The mean development times for the production of stipes differed by 7 days and were 11 and 18 days for populations 9420WT and 9421-WT, respectively. Similarly, population 9420-WT produced stipes with apical invaginations and stipes with expanding apical tips across an earlier range of days than did population 9421-WT (Fig. 1B and C). The mean development times for the production of invaginated stipes were 16 and 27 days for populations 9420-WT and 9421-WT, respectively. Mean development times for expanded stipes were 18 and 30 days for populations 9420-WT and 9421-WT, respectively. Differences between populations for the two developmental stages were 11 to 12 days. Population 9420-WT produced mature apothecia across an earlier range of days after exposure to $15^{\circ} \mathrm{C}$ than did population 9421-WT (Fig.

TABLE 1. Mean development times, variances, and rates for four stages of apothecium development for Monilinia vaccinii-corymbosi populations 9420WT and 9421-WT ${ }^{\mathrm{y}}$ from early- and late-fruiting blueberry cvs. Weymouth and Jersey, respectively

\begin{tabular}{lcccc}
\hline $\begin{array}{l}\text { Developmental } \\
\text { stage }\end{array}$ & Population & $\begin{array}{c}\text { Development } \\
\text { time (days) }\end{array}$ & $\begin{array}{c}\text { Variance } \\
\text { (days) }\end{array}$ & $\begin{array}{c}\text { Rate } \\
\text { (no./day) }\end{array}$ \\
\hline $\begin{array}{l}\text { Newly } \\
\quad \text { formed stipes }\end{array}$ & $9420-\mathrm{WT}$ & $14.1 \mathrm{~b}^{\mathrm{z}}$ & $26.6 \mathrm{~b}$ & $0.50 \mathrm{a}$ \\
$\quad$ Invaginated & $9421-\mathrm{WT}$ & $21.8 \mathrm{a}$ & $69.7 \mathrm{a}$ & $0.15 \mathrm{~b}$ \\
$\quad$ stipes & $9421-\mathrm{WT}$ & $33.0 \mathrm{a}$ & $42.1 \mathrm{a}$ & $0.30 \mathrm{a}$ \\
$\quad$ Expanded & $9420-\mathrm{WT}$ & $21.8 \mathrm{~b}$ & $15.6 \mathrm{~b}$ & $0.35 \mathrm{a}$ \\
$\quad$ stipes & $9421-\mathrm{WT}$ & $36.7 \mathrm{a}$ & $30.1 \mathrm{a}$ & $0.21 \mathrm{~b}$ \\
$\quad$ Mature & $9420-\mathrm{WT}$ & $28.2 \mathrm{~b}$ & $11.5 \mathrm{a}$ & $0.35 \mathrm{a}$ \\
$\quad$ apothecia & $9421-\mathrm{WT}$ & $41.9 \mathrm{a}$ & $14.9 \mathrm{a}$ & $0.27 \mathrm{~b}$ \\
\hline
\end{tabular}

y Values for development times, variances, and rates are the means of three experiments of five or eight replications. Each replication consisted of 50 pseudosclerotia. Values for rates were calculated from Gompertztransformed data.

${ }^{\mathrm{z}}$ Within developmental stages, populations with a letter in common do not differ significantly according to the Student-Newman-Keuls' test $(\alpha=0.05)$ for each analysis of development time, variance, or rate. 
1D). The average time required to produce a mature apothecium was 11 days earlier for population 9420-WT. The mean development times were 25 and 35 for populations 9420-WT and 9421WT, respectively.

Differences in development rates for fungal populations. The cumulative plot of the relative number of development structures present on each day was a sigmoid curve that was asymmetrical around the inflection point (Fig. 2A through D). The development for each stage of germination was more rapid for times before the inflection point than after the inflection point. Differences in development rates for Gompertz-transformed data were significant at all stages of germination $(P<0.001$ for individual analyses of experiments; $P=0.01$ to 0.03 for combined analyses of experiments); the greatest difference was in stipe production (Table 1). The rate for the production of stipes was 3.3 times greater for population 9420-WT than for population 9421-WT. Values for population 9420-WT for the other stages of development were 1.3 to 1.7 times larger.

The expansion of apical tips over time was exponential (Fig. 3). A log-transformation of the width of apices linearized the relationship between apical width and time. Rates at which apical tips expanded to form mature, fully formed cups differed significantly between populations $(P<0.001$ for individual analyses of experiments; $P=0.001$ for combined analyses). Above-ground stipes of population $9420-\mathrm{WT}$ expanded to form mature cups $37 \%$ faster than did those of population 9421-WT. Expansion rates of log-transformed values were 0.07 and $0.05 \mathrm{~mm} /$ day for fungal populations 9420-WT and 9421-WT, respectively. In combined analyses, x-intercepts for populations $9420-\mathrm{WT}$ and $9421-\mathrm{WT}$ were signifi-

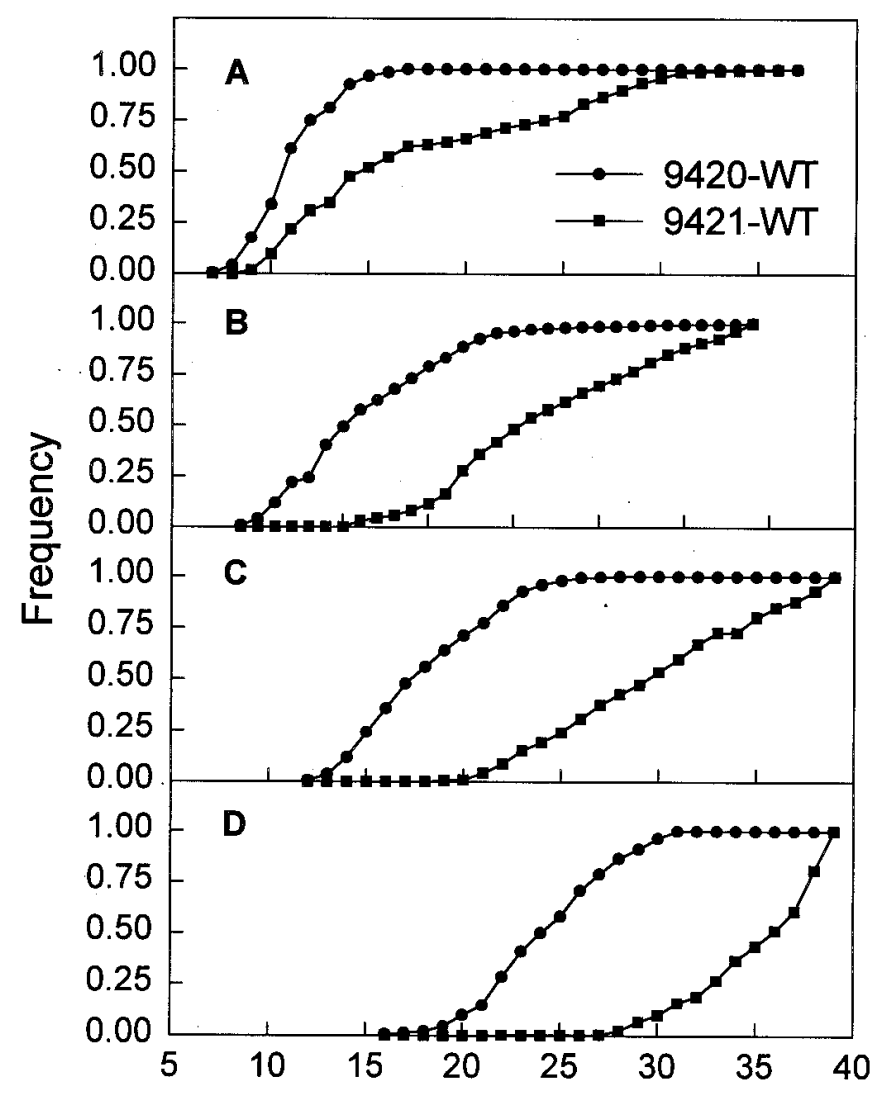

Days at $15 \mathrm{C}$

Fig. 2. Cumulative formation of A, newly formed stipes; $\mathbf{B}$, invaginated stipes; C, expanding stipes; or D, mature apothecia from pseudosclerotia of Monilinia vaccinii-corymbosi. Populations 9420-WT and 9421-WT were collected from early- and late-maturing blueberry cvs. Weymouth and Jersey, respectively. Distributions are for the development of 400 pseudosclerotia from each population in experiment I. cantly different $(P=0.02)$ and represent an 11 -day difference in development times.

Artificial inoculations. Differences in timing of apothecia formation from pseudosclerotia produced by artificial inoculation were significant $(P=0.006)$. The average development times for apothecia produced from isolates of fungal populations 9420-WT and 9421-WT were 32 and 48 days, respectively (Fig. 4). In addition, the range of days across which apothecia derived from 9421-WT developed was about five times greater than that for population 9420-WT.

Comparison of morphological traits. The morphology of the apothecium differed for populations 9420-WT and 9421-WT

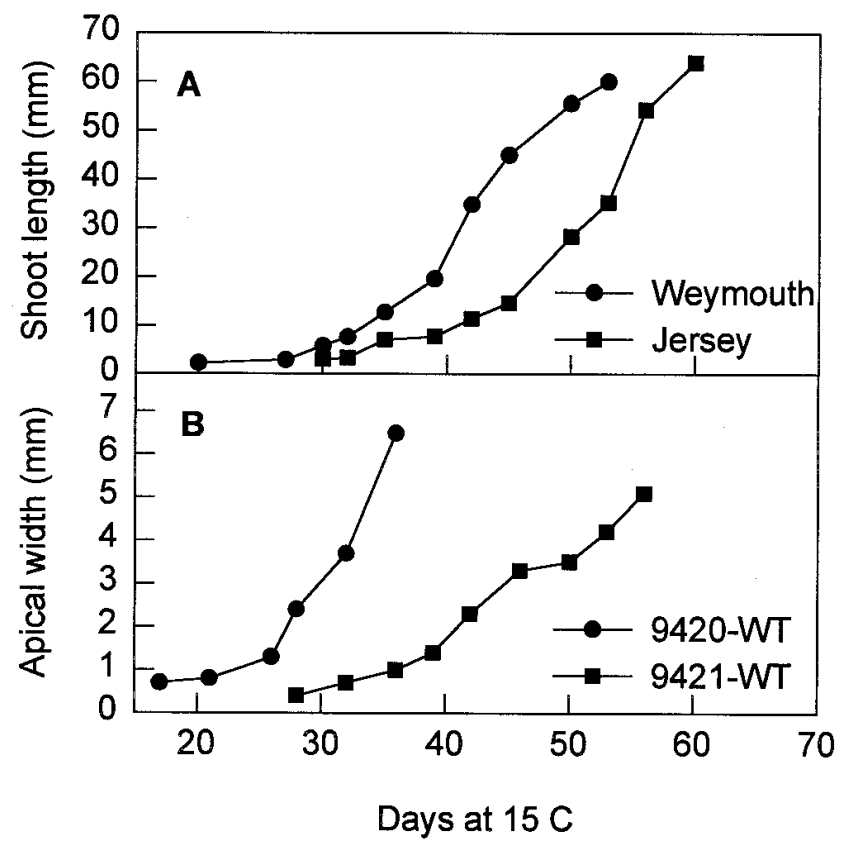

Fig. 3. A, Elongation of shoots of blueberry cvs. Weymouth and Jersey, and B, expansion of stipe apices of populations 9420-WT and 9421-WT of Monilinia vaccinii-corymbosi at $15^{\circ} \mathrm{C}$. Shoot length for each cultivar is the average of five replications of 10 shoots. Apical widths of the pathogen are the averages of five replications of 10 stipes.

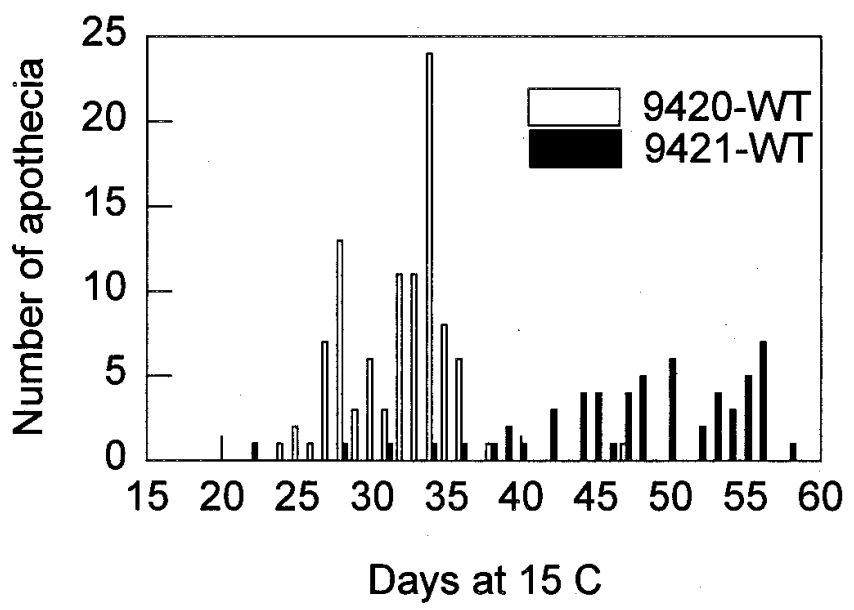

Fig. 4. Daily formation of mature apothecia from pseudosclerotia of Monilinia vaccinii-corymbosi produced in artificial inoculations of cv. Jersey. Populations 9420-WT and 9421-WT were collected from early- and late-maturing blueberry cvs. Weymouth and Jersey, respectively. Distributions are for the development of 60 pseudosclerotia from each pathogen population. The mean and variance of the distribution for population 9420-WT were 32 and 11 days, respectively. For population 9421-WT, they were 48 and 61 days, respectively. 
(Table 2). Differences in height of an apothecium between populations were significant $(P=0.01)$ as were differences between populations for width and length of the stalk that supports the cup portion of the apothecium $(P=0.01$ and 0.004 , respectively). Average height of an apothecium for population 9421-WT was $10.6 \mathrm{~mm}$, $14 \%$ taller than that of population 9420-WT (Table 2). The average length of the stalk supporting the apothecium cup was $7.2 \mathrm{~mm}$ and $20 \%$ longer than the length of stalks produced by population 9420-WT (Table 2). In contrast, population 9420-WT produced apothecia with stalks that were $0.3 \mathrm{~mm}$ wider than those of population 9421-WT. Morphological dimensions of the apothecium cup (i.e., diameter of the cup and inner and outer depth of the cup) did not differ for fungal populations ( $P=0.3$ to 0.8 ).

Vegetative and floral bud development of host cultivars. The pattern of shoot elongation for blueberry cvs. Weymouth and Jersey was similar (Fig. 3). The rates of increase in shoot length were 0.45 and $0.47 \mathrm{~mm} /$ day for Weymouth and Jersey, respectively, and were not statistically different $(P=0.60$ for combined analyses). However, the $\mathrm{x}$-intercept, which reflects the timing of shoot elongation, indicates that the elongation of shoots of cv. Weymouth preceded that of Jersey by $\sim 8$ days in field and greenhouse experiments. Similarly, Weymouth produced fully formed, open flowers 11 days earlier than did Jersey.

\section{DISCUSSION}

This study addresses two aspects of the disease cycle of $M$. vaccinii-corymbosi: variation in timing of apothecium development within and between populations of the pathogen and differences in the timing of development of susceptible host tissue between two blueberry cultivars. The underlying objectives of the study were to determine whether differences in early development exist between cultivars, and whether there is evidence of adaptation of pathogen populations to the phenology of different cultivars.

Results from four experiments conducted over a 2-year period show that 8- to 16-day differences in the initiation and rate of apothecium development, and likely ascospore production, exist between $M$. vaccinii-corymbosi populations from early- and latematuring blueberry cultivars. The direction and magnitude of these differences were similar to differences in the phenologies found for host cultivars from which the pathogen populations were collected. Buds of cv. Weymouth began to break and elongate 4 to 16 days earlier than those of Jersey.

Three possible hypotheses exist to explain the differences observed among pathogen populations. First, pathogen phenology could be the result of the genotype of the infected host (i.e., phenotypic plasticity) (13). For example, any M. vaccinii-corymbosi isolate that infects $\mathrm{cv}$. Weymouth would produce pseudosclerotia with an early phenology. This could be the result of pseudosclerotia maturing earlier in the season and entering into a dormancy period before those from later-maturing cultivars. Other host characteristics, such as susceptibility or fruit chemistry, could potentially alter the patterns of germination of pseudosclerotia, irrespective of fungal genotype. Phenotypic plasticity is an unlikely explanation because differences in pseudosclerotial germination and apothecial development of randomly selected isolates inoculated in a common host background were the same as differences seen among field-collected pseudosclerotia in different blueberry cultivars.
A second hypothesis is that germination is regulated indirectly through microenvironmental cues controlled by the host. For example, carpogenic germination of sclerotia of Sclerotinia sclerotiorum begins as the host canopy closes and creates a microclimate optimum for germination (1). It has been demonstrated that pseudosclerotial germination in $M$. vaccinii-corymbosi is dependent on several environmental factors, including a chilling period, adequate moisture, and proper temperatures $(5,16,17)$. If the differences in host phenology were sufficient to create distinct microclimates, the timing of ascospore production could be regulated by host development. This seems an unlikely scenario for $M$. vaccinii-corymbosi, because differences in the phenology of apothecium development were observed in greenhouse experiments in which microclimate variation was reduced in the experimental design.

A third hypothesis is that the differences exhibited by fungal populations are genetically based and likely the result of adaptation to blueberry cultivars with different phenologies. Pseudosclerotial germination in the greenhouse occurred in the absence of the host canopy but was correlated with host phenology. Differences in timing between pathogen populations were found in both field-collected mummies as well as second generation, laboratory-reared mummies. Variation in pseudosclerotium germination and apothecium development existed within populations (i.e., fungal populations, which were probably heterogeneous, produced individual stipes, apical invaginations, expanding tips, or mature cups over a period of days). Circumstantial evidence supporting genetic differences between fungal populations includes the fact that the host is a perennial, and the fungal populations used in this study were collected from bushes that were 40 to 50 years old. Furthermore, both populations were in relatively close proximity and were likely derived from a common population. Thus, differences in phenology of apothecium development were probably selected rather than inherent differences of populations with distinct origins. Although the evidence presented supports the hypothesis that differences between fungal populations are genetic and likely the results of host selection, additional populations from earlyand late-maturing blueberry cultivars need to be evaluated.

Despite differences in apothecium morphology between the two populations, the species description of $M$. vaccinii-corymbosi fits well in both cases (3). Preliminary results with random amplified polymorphic DNA-polymerase chain reaction did not reveal polymorphisms between the two populations, but $M$. vaccinii-corymbosi was distinguished from M. galussacia by numerous polymorphisms (J. S. Lehman and P. V. Oudemans, unpublished data). Morphological differences in apothecium height and width between 9420-WT and 9421-WT were potentially the result of selection under different environments. However, further research needs to be conducted to substantiate this conclusion.

Few studies have addressed the role of host phenology in disease incidence. In highbush blueberry, Ehlenfeldt et al. (11) found shoot length to be positively correlated with incidence of primary infection and showed that the most susceptible cultivars tested were also the most elongated. In studies by M. K. Ehlenfeldt, A. W. Stretch, and J. S. Lehman (unpublished data), the susceptibility of cv. Duke increased steadily from the close-bud state until vegetative buds had elongated $25 \mathrm{~mm}$. Beyond $25 \mathrm{~mm}$ of growth, susceptibility to primary infection decreased significantly (i.e., there was an optimum window of susceptibility). This is consistent with the findings of Woronin (25) who found that the period of sus-

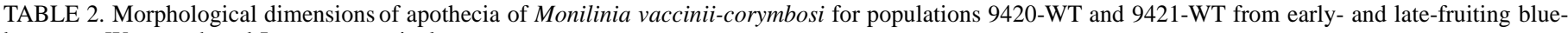
berry cvs. Weymouth and Jersey, respectively

\begin{tabular}{|c|c|c|c|c|c|c|}
\hline Population & Cup diameter & Cup depth (inner) & Cup depth (outer) & Stalk width & Stalk length & Apothecium height \\
\hline 9420-WT & $5.5 \pm 0.4 \mathrm{a}^{\mathrm{z}}$ & $2.6 \pm 0.2 \mathrm{a}$ & $3.3 \pm 0.1 \mathrm{a}$ & $1.8 \pm 0.1 \mathrm{a}$ & $6.0 \pm 0.4 \mathrm{a}$ & $9.3 \pm 0.5 b$ \\
\hline 9421-WT & $5.3 \pm 0.2 \mathrm{a}$ & $2.7 \pm 0.2 \mathrm{a}$ & $3.4 \pm 0.2 \mathrm{a}$ & $1.5 \pm 0.1 \mathrm{~b}$ & $7.2 \pm 0.4 \mathrm{~b}$ & $10.6 \pm 0.6 \mathrm{a}$ \\
\hline
\end{tabular}

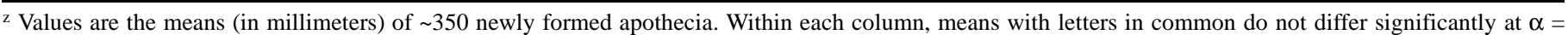
0.05 . 
ceptibility of blueberry shoots may be related to the length of time required for the young tissue to become fully cuticularized. In lowbush blueberry, Hildebrand and Braun (14) demonstrated that susceptibility of truss buds increased as bud development progressed. These studies suggest that an optimum time exists, based on host development, for the pathogen population to develop apothecia and release spores.

The fact that fungal development of populations 9420-WT and 9421-WT was distributed normally and could be described by a mean and variance suggests there is an optimum time for stages of fungal development that have significant epidemiological importance, such as the production of apothecia and ascospores. Depending on the range in periods of susceptibility, each cultivar could act as a selective force on the phenology of the pathogen population. In our study, when vegetative buds of Weymouth had expanded $40 \mathrm{~mm}, 99 \%$ of the pseudosclerotia produced in artificial inoculations with population 9420-WT had developed into mature, sporulating apothecia, whereas less than $10 \%$ of the pseudosclerotia for population 9421-WT had produced apothecia. In contrast, when buds of Jersey had expanded $40 \mathrm{~mm}$, the majority of apothecia of population 9420-WT had been present for 2.5 weeks and were beginning to decline, whereas $85 \%$ of those for population 9421-WT were present. This suggests that isolates of $M$. vaccinii-corymbosi with a phenology that corresponds to that of Weymouth would be more likely to infect than isolates that develop later. Such isolates would have a reproductive advantage and increase in frequency provided that variation in pathogen phenology (e.g., timing and rate of apothecium development) is controlled genetically.

In conclusion, our results suggest there is variation in the phenological development within and between populations of $M$. vaccinii-corymbosi. A portion of the variation between populations is under genetic control and may enable adaptation of fungal populations to the phenologies of different host cultivars. Despite the potential for pathogen adaptation, disease avoidance may provide a useful means of controlling M. vaccinii-corymbosi as long as pathogen phenological development and its variation are described for the region of host deployment. Hence, results of this study could aid in developing resistant cultivars that avoid the spring discharge of ascospores. In a broader context, this research emphasizes the role of pathogen phenology on the establishment of disease and importance of variation in phenology in the adaptation of fungal populations to host cultivars.

\section{ACKNOWLEDGMENTS}

This work was supported by a USDA Specific Cooperative Agreement grant. We thank C. Ferrier for technical assistance.

\section{LITERATURE CITED}

1. Abawi, G. S., and Grogan, R. G. 1979. Epidemiology of diseases caused by Sclerotinia species. Phytopathology 69:899-904.

2. Batra, L. R. 1983. Monilinia vaccinii-corymbosi (Sclerotiniaceae): Its bi- ology on blueberry and comparison with related species. Mycologia 75: 131-152.

3. Batra, L. R. 1991. World Species of Monilinia (Fungi): Their Ecology, Biosystematics and Control. J. Cramer, Berlin.

4. Brewster, V., Stretch, A. W., and Ehlenfeldt, M. K. 1995. A technique for producing conidia of Monilinia vaccinii-corymbosi on artificial media. (Abstr.) Phytopathology 85:1200.

5. Bristow, P. R., 1979. Mummy berry disease: Mummy germination. Pages 163-169 in: Proc. 4th North Am. Blueberry Res. Workers Conf. Division of Continuing Education, University of Arkansas, Fayetteville.

6. Burdon, J. J. 1987. Diseases and Plant Population Biology. Cambridge University Press, Cambridge.

7. Campbell, C. L., and Madden, L. V. 1990. Introduction to Plant Disease Epidemiology. John Wiley \& Sons, New York.

8. Caruso, F. L., and Ramsdell, D. C. 1995. Compendium of Blueberry and Cranberry Diseases. The American Phytopathological Society, St. Paul, MN.

9. Cochran, W. G., and Cox, G. M. 1957. Experimental Designs. 2nd ed. John Wiley \& Sons, New York.

10. Darrow, G. M., and Scott, D. H. 1966. Varieties and their characteristics. Pages 94-110 in: Blueberry Culture. P. Eck and N. F. Childers, eds. Rutgers University Press, New Brunswick, NJ.

11. Ehlenfeldt, M. K., Stretch, A. W., and Brewster, V. 1996. Genetic and morphological factors influence mummy berry blight resistance in highbush blueberry cultivars. HortScience 31:252-254.

12. Hancock, J. F., and Draper, A. D. 1989. Blueberry culture in North America. HortScience 24:551-556.

13. Hartl, D. L., and Clark, A. G. 1989. Population Genetics. 2nd ed. Sinauer Associates, Inc., Sunderland, MA.

14. Hildebrand, P. D., and Braun, P. G. 1991. Factors affecting infection of lowbush blueberry by ascospores of Monilinia vaccinii-corymbosi. Can. J. Plant Pathol. 13:232-240.

15. Lehman, J. S., and Oudemans, P. V. 1995. Differences in rates of apothecium development between populations of Monilinia vaccinii-corymbosi. (Abstr.) Phytopathology 85:1133.

16. Milholland, R. D. 1974. Factors affecting apothecium development of Monilinia vaccinii-corymbosi from mummified highbush blueberry fruit. Phytopathology 64:296-300.

17. Milholland, R. D. 1977. Sclerotium germination and histopathology of Monilinia vaccinii-corymbosi on highbush blueberry. Phytopathology 67: 848-854.

18. Nelson, J. W., and Bittenbender, H. C. 1971. Mummy berry disease occurrence in a blueberry selection test planting. Plant Dis. Rep. 55:651-653.

19. Nyquist, W. E. 1991. Estimation of heritability and prediction of selection response in plant populations. Crit. Rev. Plant Sci. 10:235-322.

20. Pepin, H. S., and Toms, H. N. W. 1969. Susceptibility of highbush blueberry varieties to Monilinia vaccinii-corymbosi. Phytopathology 59:18761878.

21. Ramsdell, D. C., Nelson, J. W., and Myers, R. L. 1974. An epidemiological study of mummy berry disease of highbush blueberry. Phytopathology 64:222-228.

22. Ramsdell, D. C., Nelson, J. W., and Myers, R. L. 1975. Mummy berry disease of highbush blueberry: Epidemiology and control. Phytopathology 65:229-232.

23. Stretch, A. W., Ehlenfeldt, M. K., and Brewster, V. 1995. Mummy berry disease blight resistance in highbush blueberry cultivars. HortScience 30: 589-591.

24. Varney, E. H., and Stretch, A. W. 1966. Diseases and their control. Pages 236-279 in: Blueberry Culture. P. Eck and N. F. Childers, eds. Rutgers University Press, New Brunswick, NJ.

25. Woronin, M. 1888. Über die sclerotienkrankheit der vaccinieen-beeren. Mem. Acad. Imp. Sci. St. Petersbourg 36(6):1-49. 